\title{
Current Status of Patient Education in the Management of Atopic Dermatitis in Korea
}

\author{
Min Kyung Lee ${ }^{1}$, Ju-Hee Seo ${ }^{2}$, Howard Chu ${ }^{1}$, Hyunjung Kim³ ${ }^{3}$, Yong Hyun Jang ${ }^{4}$, Jae Won Jeong ${ }^{5}$, \\ Hye Yung Yum ${ }^{6}$, Man Yong Han ${ }^{7}$, Ho Joo Yoon ${ }^{8}$, Sang-Heon Cho ${ }^{9}$, Yeong Ho Rha ${ }^{10}$, Jin-Tack Kim ${ }^{11}$, \\ Young Lip Park ${ }^{12}$, Seong Jun Seo ${ }^{13}$, Kwang Hoon Lee ${ }^{1}$, and Chang Ook Park ${ }^{1}$ \\ ${ }^{1}$ Department of Dermatology, Severance Hospital, Cutaneous Biology Research Institute, Yonsei University College of Medicine, Seoul; \\ ${ }^{2}$ Department of Pediatrics, Dankook University Hospital, Cheonan; \\ ${ }^{3}$ Department of Dermatology, Atopy Clinic, Seoul Medical Center, Seoul; \\ ${ }^{4}$ Department of Dermatology, School of Medicine, Kyungpook National University, Daegu; \\ ${ }^{5}$ Department of Internal Medicine, Inje University Ilsan Paik Hospital, Goyang; \\ ${ }^{6}$ Department of Pediatrics, Atopy Clinic, Seoul Medical Center, Seoul; \\ ${ }^{7}$ Department of Pediatrics, CHA Bundang Medical Center, CHA University School of Medicine, Seongnam; \\ ${ }^{8}$ Department of Internal Medicine, Hanyang University College of Medicine, Seoul; \\ ${ }^{9}$ Department of Internal Medicine, Seoul National University College of Medicine, Seoul; \\ ${ }^{10}$ Department of Pediatrics, School of Medicine, Kyung Hee University, Seoul; \\ ${ }^{11}$ Department of Pediatrics, College of Medicine, the Catholic University of Korea, Seoul; \\ ${ }^{12}$ Department of Dermatology, Soonchunhyang University College of Medicine, Seoul; \\ ${ }^{13}$ Department of Dermatology, Chung-Ang University Hospital, Seoul, Korea.
}

Patient education is important for successful management of atopic dermatitis; however, due to limited time and resources, patient education remains insufficient. This study aimed to investigate the current state of education provided by Korean dermatologists, pediatric allergists, and allergists to patients with atopic dermatitis. A questionnaire survey consisting of items regarding educational programs for patients with atopic dermatitis was conducted via e-mail. In total, 153 participants responded to the questionnaires, and $26.8 \%$ indicated that they have had separate educational programs. The workforce involved in the educational program included nurses, residents or fellows, dieticians, pharmacists, and clinical psychologists. Most education protocols addressed the characteristics and natural course of atopic dermatitis and environmental management. Overall, $96.7 \%$ of the participants replied that an additional charge is needed for education; moreover, additional assistance from an academic society or association, in the form of medical staff, organized data, and advertisement, is required to develop and provide a well-structured educational program. A standardized education protocol will effectively provide appropriate education for patients with atopic dermatitis. Arrangement of education fees, covered by the National Health Insurance Service, will lead to the establishment of a structured educational program and participation of an additional medical workforce.

Key Words: Atopic dermatitis, education, Korea, questionnaire survey

Received: January 17, 2019 Revised: May 13, 2019

Accepted: May 19, 2019

Corresponding author: Chang Ook Park, MD, PhD, Department of Dermatology, Severance Hospital, Cutaneous Biology Research Institute, Yonsei University College of Medicine, 50-1 Yonsei-ro, Seodaemun-gu, Seoul 03722, Korea.

Tel: 82-2-2228-2080, Fax: 82-2-393-9157, E-mail: copark@yuhs.ac

-The authors have no potential conflicts of interest to disclose.

(C) Copyright: Yonsei University College of Medicine 2019

This is an Open Access article distributed under the terms of the Creative Commons Attribution Non-Commercial License (https://creativecommons.org/licenses/ by-nc/4.0) which permits unrestricted non-commercial use, distribution, and reproduction in any medium, provided the original work is properly cited.
Atopic dermatitis $(\mathrm{AD})$ is a chronic dermatological condition with increasing prevalence, which is becoming a major social issue. ${ }^{1}$ Since the disease poses great economic burden and has a negative impact on the patient's daily life, ${ }^{2}$ long-term national treatment plans should be considered. ${ }^{3}$

A deluge of scientifically unconfirmed information from the media and alternative medicine can cause patient to misunderstand AD. ${ }^{4,5}$ Moreover, fear of medical therapy may also lead to inappropriate treatment. ${ }^{6}$ Therefore, providing proper education to patients and their caregivers is important in im- 
proving the patient's attitude toward the disease, which may ensure better treatment compliance, and eventually the overall treatment response. ${ }^{7-10}$

Although previous studies in Korea have demonstrated the need for education on $\mathrm{AD},{ }^{11}$ no study has assessed how the educational programs are provided. In this study, we administered a questionnaire to clinicians who currently treat patients with $\mathrm{AD}$ in Korea. Through this study, we aimed to assess the education status on $\mathrm{AD}$ and utilize the results as a foundation for the future development of a standardized educational program in Korea.

A survey was conducted between June and September 2017 via email to all clinicians registered with the Korean Dermatological Association (KDA); Korean Academy of Pediatric Allergy and Respiratory Disease (KAPARD); and Korean Academy of Asthma, Allergy, and Clinical Immunology (KAAACI), employed at various centers. This study was approved by the Institutional Review Board of Severance Hospital (IRB no. 4-20181018).

The questionnaire comprised of 22 questions, largely categorized under the following topics: 1) workplace; 2) presence of an educational program; 3) methodology used for the programs; and 4) necessary conditions for the implementation of programs.

The survey was sent via e-mail to 3420 clinicians, and 153 of them (44 dermatologists and 109 pediatric allergists or allergists) responded (Table 1). The average clinical experience duration was 17.88 years. Forty-eight participants (31.4\%) were from primary private clinics, $22(14.4 \%)$ were from secondary medical centers, and $82(53.6 \%)$ were from tertiary centers (university hospitals). Clinicians reported the following consultation times: 14 participants $(9.2 \%), \leq 5 \mathrm{~min}$; 56 participants (36.6\%), 6-10 min; 55 participants (35.9\%), 11-20

Table 1. Characteristics of Participants

\begin{tabular}{lc}
\hline \multicolumn{1}{c}{ Variables } & Number of participants (n, \%) \\
\hline Field of specialization & \\
Dermatology & $44(28.8)$ \\
\hline Allergy/pediatric allergy & $109(71.2)$ \\
Medical institution & \\
\hline Primary clinic & $39(25.5)$ \\
\hline Children's hospital & $9(5.9)$ \\
\hline Secondary hospital & $22(14.4)$ \\
\hline University hospital & $82(53.6)$ \\
\hline No response & $1(0.6)$ \\
Consultation/treatment time per patient & \\
$\leq 5$ min & $14(9.2)$ \\
\hline $6-10$ min & $56(36.6)$ \\
\hline $11-20$ min & $55(35.9)$ \\
\hline $21-30$ min & $28(18.3)$ \\
\hline $31-60$ min & $0(0)$ \\
\hline More than 1 hr & $0(0)$ \\
\hline
\end{tabular}

Values are presented as $n(\%)$. min; and 28 participants (18.3\%), 21-30 min. No clinician spent longer than 30 min per patient. When asked about the ideal duration for education, among the 90 participants who responded, 43 participants (47.8\%) indicated $15-30 \mathrm{~min}$ and 24 (26.7\%) indicated 30-60 min to be preferable. Several responded that $\leq 15 \mathrm{~min}$ or $\geq 60 \mathrm{~min}$ would be needed [21/90 (23.3\%) and $2 / 90(2.2 \%)$, respectively].

We then assessed if any additional educational programs were provided. Among the 153 participants, 41 (26.8\%) said a separate program was provided. Most of these responders were from university hospitals (30 participants), followed by secondary medical centers (seven participants), private clinics (three participants), and children's hospitals (two participants). Regarding the program, 33 of 41 participating clinicians (80.5\%) provided an individual-level educational program, and four (9.7\%) provided a group-level program. The remaining participants $(9.7 \%)$ provided both individual- and group-level programs (Table 2).

We asked a different set of questions to the 37 clinicians who provided individual-level educational programs. Education was most often provided at the outpatient clinic (73\%), whereas in some cases, a separate consultation room was used (27.6\%). In very few cases, either a treatment room or a special information center was used. Group-level programs were offered at various venues, including an outpatient clinic, consultation room, hospital auditorium, and patient ward (Table 2). Among the workforce involved in individual-level programs (multiple answers allowed), nurses were found to be most fre-

Table 2. Responses Regarding Individual and Group Education

\begin{tabular}{|c|c|c|c|}
\hline & $\begin{array}{l}\text { Individual } \\
\text { education }\end{array}$ & $\begin{array}{c}\text { Group } \\
\text { education }\end{array}$ & Both \\
\hline \multicolumn{4}{|l|}{ Types of medical center* } \\
\hline Primary clinic & $1(2.7)$ & $2(25)$ & - \\
\hline Children's hospital & $2(5.4)$ & - & - \\
\hline Secondary hospital & $6(16.2)$ & $1(12.5)$ & $1(25)$ \\
\hline University hospital & $28(75.7)$ & $5(62.5)$ & $3(75)$ \\
\hline \multicolumn{4}{|l|}{ Venue for education } \\
\hline Outpatient clinic & $27(73)$ & $2(25)$ & - \\
\hline Counseling office & $8(21.6)$ & $2(25)$ & - \\
\hline Others ${ }^{\dagger}$ & $2(5.4)$ & $4(50)$ & - \\
\hline \multicolumn{4}{|c|}{ Medical staff providing the education ${ }^{\ddagger}$} \\
\hline Nurses & $23(62.2)$ & $8(47.1)$ & - \\
\hline Residents or fellows & $19(51.4)$ & $3(17.6)$ & - \\
\hline Pharmacists & $5(13.5)$ & $4(23.5)$ & - \\
\hline Dieticians & $2(5.4)$ & - & - \\
\hline Clinical psychologists & $1(2.7)$ & $2(11.8)$ & - \\
\hline Others ${ }^{\ddagger}$ & $5(13.5)$ & - & - \\
\hline
\end{tabular}

Values are presented as $n(\%)$.

${ }^{*}$ Multiple answers were allowed; ${ }^{\dagger}$ Others include center (treatment room) for atopic dermatitis and asthma for individual-level education, as well as hospital auditorium and patient ward for group-level education; ${ }^{\ddagger}$ Others include cases wherein the clinician, primary investigator, or specialized nurses provided the education. 
quently involved (23 participants), followed by residents or fellows (19), dieticians (five), pharmacists (two), and clinical psychologists (one). Similar results were found for group-level programs.

We then assessed the frequency of education (Fig. 1). For the centers that provided an individual-level program, 23 of 37 centers $(62.2 \%)$ provided the program only at the time of initial diagnosis, and nine centers $(24.3 \%)$ provided the program during every consultation. While some (13.5\%) provided education one to three times annually, no center provided education more than four times a year. Regarding group-level education, among the eight centers, five $(62.5 \%)$ provided education $\leq$ six times per year; two centers, more than seven times per year; and one center provided education as needed. Individual- and group-level educational programs were provided for both the patients and their caregivers in $97.3 \%$ and $100 \%$ of the centers, respectively. In most cases (97.6\%), no extra costs were charged for additional education.

The survey also inquired about the topics covered. Details are shown in Fig. 2. Regarding the natural course of the disease, all centers addressed its chronicity. Among the 41 responders, 38 (92.7\%) reported that the education included disease characteristics of each age group, and $36(87.8 \%)$ reported that the associations with other allergic diseases were also included. For daily skin care, more than $92.7 \%$ of the responders said they covered topics such as lukewarm baths, moisturizer use,

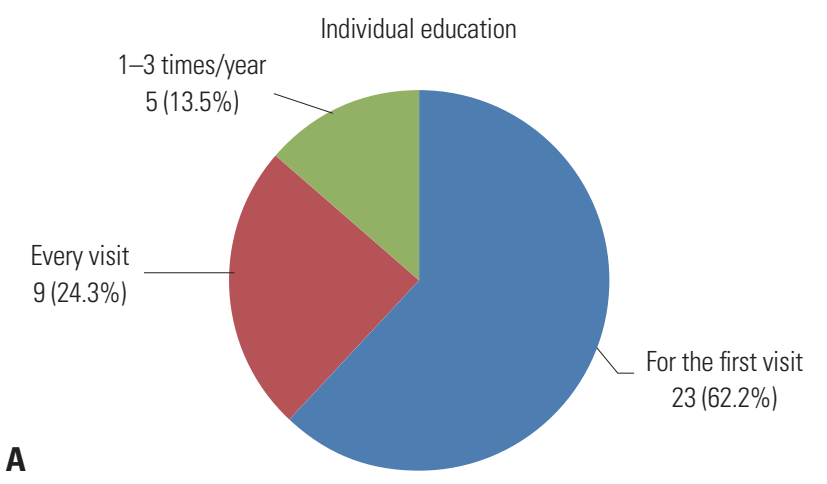

Group education

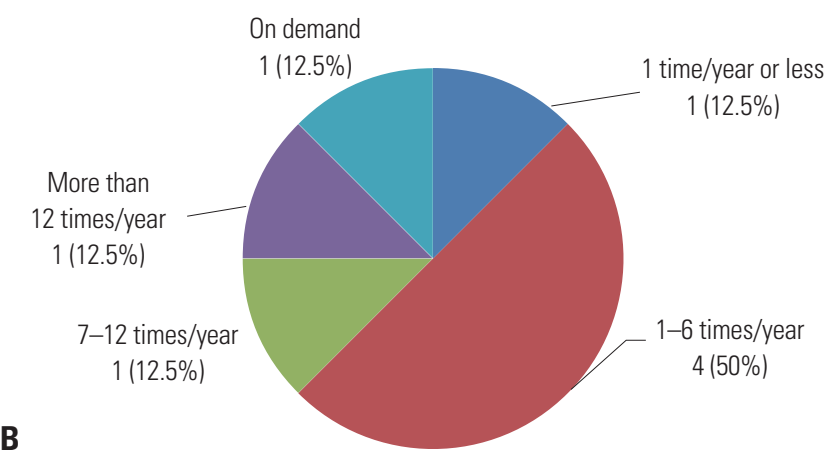

Fig. 1. Frequency of $(A)$ individual- and $(B)$ group-level education. and coping with the urge to scratch.

Regarding the use of medications, 31 of 41 (75.6\%) responders stated that proper application of topical ointments was shown through demonstration. Similarly, 24 responders (58.5\%) stated that education covered wet-wrap therapy, in which $41.7 \%$ were pediatricians/allergists and $58.3 \%$ were dermatologists. Of the 41 participants, 36 (87.8\%) responded that they covered proper ointment use upon symptomatic exacerbations. These indicate a relatively lower rate of detailed instructions on medication use. For the management of environmental and aggravating factors, 39 (95.1\%) responders stated that the programs covered temperature and humidity management, 34 (83\%) reported the benefits of wearing cotton-based clothing, and 35 (85.4\%) reported the control of exposure to common allergens.

Regarding diet, only 20 responders $(48.8 \%)$ said they had surveyed patients' diets. Thirty-seven $(90.2 \%)$ indicated that they advised elimination of food that exacerbate symptoms, and $29(70.7 \%)$ said the programs included education on alternative foods. Most responders (92.7\%) advised against unwarranted dietary restrictions. In terms of nutritional counseling, in contrast to $27.3 \%$ of dermatologists, $73.3 \%$ of allergists said they understood the patients' nutritional status. Meanwhile, only nine (22\%) provided psychologic counseling.

We also assessed the sources of data used for the programs, and multiple answers were allowed. Thirty-three (80.5\%) responders stated that they developed their own educational materials. Eighteen participants utilized materials from academic societies or associations. Oral presentation was the main delivery method (35 participants), followed by handouts (32 participants) and video-based information (11 participants). Four participants used other methods, including information panels, tools, and presentation slides. Objective indices, such as Eczema Area Severity Index (EASI) and SCORing Atopic Dermatitis (SCORAD), were used by $41.5 \%$ of the responders.

For 109 participants who did not provide the educational program, 58 out of 90 participants (64.4\%) preferred individual-level education, whereas only 10 participants (11.1\%) preferred group-level education. The remaining $24.4 \%$ of the participants indicated that both educational programs were required.

Overall, $96.7 \%$ of the participants said an additional charge was needed for education on AD. Furthermore, they mentioned that additional assistance from an academic society or association, in the form of medical staff, organized data, and advertisement, was required to provide a well-structured educational program. Eighty-seven out of 90 participants (96.7\%) were willing to provide education for patients with $\mathrm{AD}$ if an appropriate consultation fee was provided. Therefore, with an additional budget for education on $\mathrm{AD}$, more patients will surely benefit.

According to the results, only $26.8 \%$ of the centers scheduled additional time aside from the clinics to provide an appropriate education. Most of them were university hospitals, likely due to the smaller number of clinicians from private clin- 


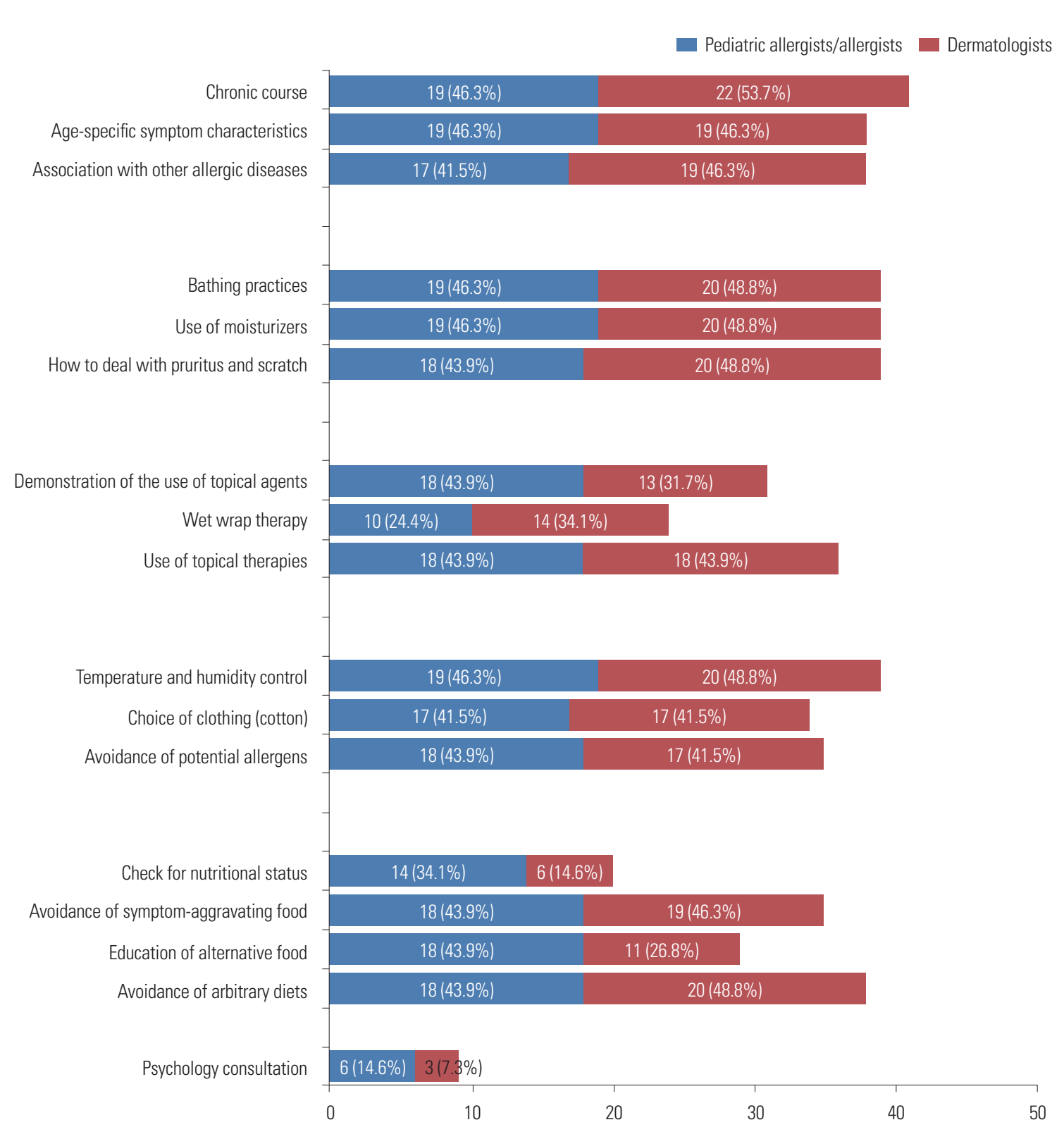

Fig. 2. Detailed educational contents included in the programs.

ics in this study and greater academic interest in patient education in university hospitals. Most participants provided individual-level education, held mostly at an outpatient clinic. There was only one case where a dedicated venue for patient education was available, reflecting the scarcity of appropriate venues. Nurses primarily comprised most of the workforce involved in the programs.

Even if a separate education was provided, it was usually performed only at the initial visit. Similarly, for group-level education, most centers provided only six sessions or less per year. The appropriate management of chronic conditions requires continuous and repetitive patient education. ${ }^{12,13}$ However, education was not up to these standards in real clinical settings. Furthermore, more than one-third of the respondents reported that the average consultation time for each patient was 5-10 min, and no one spent longer than 30 min per patient. Meanwhile, the majority indicated that education should last for longer than $15 \mathrm{~min}$, some even suggesting that education should be $30 \mathrm{~min}$ or longer. Therefore, although clinicians realize the need for additional time for education, it may be difficult to achieve under the current circumstances.

Regarding the education method, oral communication and handouts were most commonly utilized. Indeed, audio-visual materials can significantly improve patient understanding, ${ }^{14,15}$ but most centers used self-developed handouts. Therefore, a unified and reliable educational material must be developed.

The educational programs sought to thoroughly explain various aspects of the disease and its management. However, not many programs included information on the application of ointment, diet, or psychological aspects. Daily skin care is im- 
portant, and direct or video demonstration would be more effective in providing adequate education for bathing and skin care.$^{16}$ It is well-known that topical therapy is fundamental; however, it should be adjusted according to the patient's conditions. Furthermore, due to the lack of understanding among caregivers, most of them seek dietary therapy to cope with $\mathrm{AD}$. A survey-based study ${ }^{17}$ showed that about $43 \%$ of the responders indicated dietary management to be most important, and more than half of the patients previously had tried dietary restriction. Dietary restrictions must be made only with confirmed food allergy, ${ }^{18}$ and when needed, education on alternative nutrition is important to prevent malnutrition. Therefore, dieticians must also be involved in the education. ${ }^{19}$

The deleterious effect of psychological stress in $\mathrm{AD}$ has been well-recognized. $\mathrm{AD}$ results in social intimidation and reduced quality of life. ${ }^{20,21}$ Furthermore, psychological comorbidities, including anxiety and depression, are more prevalent in patients with $\mathrm{AD} .{ }^{22}$ Stress then worsens the condition, leading to a vicious cycle. Also, psychological intervention and behavioral therapy against itch and scratching have been reported to improve the condition. ${ }^{23,24}$ In summary, treatment of $\mathrm{AD}$ needs to be supported by an educational program consisting of a team of different professionals, including dermatologists, pediatric allergists, nurses, psychological clinicians, and dieticians, and should endeavor towards a multidisciplinary approach. ${ }^{25}$

Most of the clinicians who participated in this study asserted a need for an additional consultation fee for the education of $\mathrm{AD}$, as a more proper type of education can be provided after the arrangement. Several issues, including limited time and inadequate medical staff, reportedly prevented clinicians from actively providing appropriate education in Korea. Through recognition of such needs, an appropriate consultation fee has already been adjusted for several chronic diseases, including diabetes, asthma, and cardiovascular disease, in Korea. Since $\mathrm{AD}$ is also a chronic disease with high prevalence, patients with $\mathrm{AD}$ would surely benefit from the education..$^{26}$

In Korea, five different municipal governments have established educational and informational centers for $\mathrm{AD}$ and asthma. However, additional manpower and time are needed to properly carry out the programs, and a more tailored protocol according to the patient's age or severity is required. ${ }^{27-29}$ As the importance of education in $\mathrm{AD}$ is emphasized, structured educational programs are being provided globally, especially in Europe and the United States, which are supported and funded by various organizations. ${ }^{30,31}$ Likewise, the arrangement of education fees will lead to the establishment of a structured educational program with additional medical staff in Korea.

Due to the small sample size, low response rate, and possible selection bias associated with the survey, the results do not fully represent all clinicians who manage patients with AD. Therefore, a multi-center study involving a larger number of clinicians should be performed in the future. We hope that our data will be used as baseline data for the future develop- ment of standardized education and consultation protocol for patients with $\mathrm{AD}$.

\section{ACKNOWLEDGEMENTS}

This work was supported by the National Research Foundation of Korea (NRF) grant funded by the Korea government (Ministry of Scienceand ICT) (No. NRF-2017R1A2B4009568).

\section{AUTHOR CONTRIBUTIONS}

Conceptualization: Man Yong Han, Yeong Ho Rha, and Chang Ook Park. Data curation: Ju-Hee Seo and Yong Hyun Jang. Formal analysis: Min Kyung Lee and Jae Won Jeong. Funding acquisition: Chang Ook Park. Investigation: Hyunjung Kim and Yeong Ho Rha. Methodology: Hyunjung Kim and Hye Yung Yum. Project administration: Man Yong Han and Chang Ook Park. Resources: Man Yong Han and Chang Ook Park. Software: Min Kyung Lee and Ju-Hee Seo. Supervision: Man Yong Han, Sang-Heon Cho, Jin-Tack Kim, Young Lip Park, Seong Jun Seo, Kwang Hoon Lee, and Chang Ook Park. Validation: Yong Hyung Jang and Hye Yung Yum. Visualization: Ho Joo Yoon and Jin-Tack Kim. Writing - original draft: Min Kyung Lee and Howard Chu. Writing - review \& editing: Ju-Hee Seo, Howard Chu, and Chang Ook Park.

\section{ORCID iDs}

Min Kyung Lee https://orcid.org/0000-0001-7622-3276 Ju-Hee Seo https://orcid.org/0000-0001-6783-2942 Howard Chu https://orcid.org/0000-0001-5061-5351 Hyunjung Kim https://orcid.org/0000-0001-5125-667X Yong Hyun Jang https://orcid.org/0000-0003-1706-007X Jae Won Jeong https://orcid.org/0000-0001-5340-1957 Hye Yung Yum https://orcid.org/0000-0002-3997-4094 Man Yong Han https://orcid.org/0000-0002-9077-5779 Ho Joo Yoon https://orcid.org/0000-0002-4645-4863 Sang-Heon Cho https://orcid.org/0000-0002-7644-6469 Yeong Ho Rha https://orcid.org/0000-0001-5593-5020 Jin-Tack Kim https://orcid.org/0000-0001-6903-0142 Young Lip Park https://orcid.org/0000-0002-6532-3156 Seong Jun Seo https://orcid.org/0000-0003-2915-839X Kwang Hoon Lee https://orcid.org/0000-0002-4361-1819 Chang Ook Park https://orcid.org/0000-0003-3856-1201

\section{REFERENCES}

1. Spergel JM. Epidemiology of atopic dermatitis and atopic march in children. Immunol Allergy Clin North Am 2010;30:269-80.

2. Morren MA, Przybilla B, Bamelis M, Heykants B, Reynaers A, Degreef $\mathrm{H}$. Atopic dermatitis: triggering factors. J Am Acad Dermatol 1994;31(3 Pt 1):467-73.

3. Kim JE, Kim HJ, Lew BL, Lee KH, Hong SP, Jang YH, et al. Consensus guidelines for the treatment of atopic dermatitis in Korea (Part I): general management and topical treatment. Ann Dermatol 2015;27:563-77.

4. Chin HW, Jang HS, Jang BS, Jo JH, Kim MB, Oh CK, et al. A study on utilization of alternative medicine for patients with atopic dermatitis. Korean J Dermatol 2005;43:903-11.

5. Kim JK, Kim JH, Lim DH, Son BK. Qualitative assessment of atopic dermatitis-related websites. Pediatr Allergy Respir Dis 2007;17:282-8. 
6. Li AW, Yin ES, Antaya RJ. Topical corticosteroid phobia in atopic dermatitis: a systematic review. JAMA Dermatol 2017;153:1036-42.

7. Shin JY, Kim DW, Park CW, Seo SJ, Park YL, Lee JR, et al. An educational program that contributes to improved patient and parental understanding of atopic dermatitis. Ann Dermatol 2014;26:66-72.

8. Sidbury R, Tom WL, Bergman JN, Cooper KD, Silverman RA, Berger TG, et al. Guidelines of care for the management of atopic dermatitis: section 4. Prevention of disease flares and use of adjunctive therapies and approaches. J Am Acad Dermatol 2014;71:1218-33.

9. Pustišek N, Šitum M, Vurnek Živković M, Ljubojević Hadžavdić S, Vurnek M, Niseteo T. The significance of structured parental educational intervention on childhood atopic dermatitis: a randomized controlled trial. J Eur Acad Dermatol Venereol 2016;30:806-12.

10. Jang YH, Lee JS, Kim SL, Song CH, Jung HD, Shin DH, et al. A family-engaged educational program for atopic dermatitis: a sevenyear, multicenter experience in Daegu-Gyeongbuk, South Korea. Ann Dermatol 2015;27:383-8.

11. Yum HY, Han KO, Park J, Kang MY, Chang SI, Cho SH, et al. Improvement in disease knowledge through an education program of atopic dermatitis. Korean J Asthma Allergy Clin Immunol 2012;32: 21-5.

12. Heratizadeh A, Werfel T, Wollenberg A, Abraham S, Plank-Habibi S, Schnopp C, et al. Effects of structured patient education in adults with atopic dermatitis: multicenter randomized controlled trial. J Allergy Clin Immunol 2017;140:845-53.

13. Staab D, Diepgen TL, Fartasch M, Kupfer J, Lob-Corzilius T, Ring J, et al. Age related, structured educational programmes for the management of atopic dermatitis in children and adolescents: multicentre, randomised controlled trial. BMJ 2006;332:933-8.

14. Barbarot S, Gagnayre R, Bernier C, Chavigny JM, Chiaverini C, Lacour JP, et al. [A guide for education programs in atopic dermatitis]. Ann Dermatol Venereol 2007;134:121-7.

15. Agner T. Compliance among patients with atopic eczema. Acta Derm Venereol Suppl (Stockh) 2005;(215):33-5.

16. Niebel G, Kallweit C, Lange I, Fölster-Holst R. [Direct versus videoaided parent education in atopic eczema in childhood as a supplement to specialty physician treatment. A controlled pilot study]. Hautarzt 2000;51:401-11.

17. Lee JB, Rha YH, Choi SH. A questionnaire survey of care-givers' understanding of atopic dermatitis. Korean J Asthma Allergy Clin Immunol 2009;29:179-85.

18. Muraro A, Halken S, Arshad SH, Beyer K, Dubois AE, Du Toit G, et al. EAACI food allergy and anaphylaxis guidelines. Primary prevention of food allergy. Allergy 2014;69:590-601.

19. Nicol NH, Ersser SJ. The role of the nurse educator in managing atopic dermatitis. Immunol Allergy Clin North Am 2010;30:369-83.

20. Chung SW, Chang EY, Lee HC, Shin MY, Kim BE, Ahn KM, et al. The relationships among severity score, behavioral problem, parental stress, maternal depression, and social support in children with atopic dermatitis. Korean J Asthma Allergy Clin Immunol 2005; 25:39-44.

21. Finlay AY. Measures of the effect of adult severe atopic eczema on quality of life. J Eur Acad Dermatol Venereol 1996;7:149-54.

22. Senra MS, Wollenberg A. Psychodermatological aspects of atopic dermatitis. Br J Dermatol 2014;170 Suppl 1:38-43.

23. Ehlers A, Stangier U, Gieler U. Treatment of atopic dermatitis: a comparison of psychological and dermatological approaches to relapse prevention. J Consult Clin Psychol 1995;63:624-35.

24. Norén P, Melin L. The effect of combined topical steroids and habitreversal treatment in patients with atopic dermatitis. $\mathrm{Br} J$ Dermatol 1989;121:359-66.

25. Boguniewicz M, Nicol N, Kelsay K, Leung DY. A multidisciplinary approach to evaluation and treatment of atopic dermatitis. Semin Cutan Med Surg 2008;27:115-27.

26. de Bes J, Legierse CM, Prinsen CA, de Korte J. Patient education in chronic skin diseases: a systematic review. Acta Derm Venereol 2011;91:12-7.

27. Ring J, Alomar A, Bieber T, Deleuran M, Fink-Wagner A, Gelmetti C, et al. Guidelines for treatment of atopic eczema (atopic dermatitis) Part II. J Eur Acad Dermatol Venereol 2012;26:1176-93.

28. Lim MS, Lee CH, Sim S, Hong SK, Choi HG. Physical activity, sedentary habits, sleep, and obesity are associated with asthma, allergic rhinitis, and atopic dermatitis in Korean Adolescents. Yonsei Med J 2017;58:1040-6.

29. Lee J, Lee H, Noh S, Bae BG, Shin JU, Park CO, et al. Retrospective analysis on the effects of house dust mite specific immunotherapy for more than 3 years in atopic dermatitis. Yonsei Med J 2016;57: 393-8.

30. Sy W, Lamb AJ. Atopic dermatitis disease education. Adv Exp Med Biol 2017;1027:179-84.

31. Stalder JF, Bernier C, Ball A, De Raeve L, Gieler U, Deleuran M, et al. Therapeutic patient education in atopic dermatitis: worldwide experiences. Pediatr Dermatol 2013;30:329-34. 